J. Lake Sci. (湖泊科学) , $2007,19(6): 664-669$

http://www. jlakes.org. E-mail:jlakes@ niglas. ac.cn

(c) 2007 by Journal of Lake Sciences

\title{
太湖鱼类区系变化和渔获物分析”
}

\author{
朱松泉, 刘正文, 谷孝鸿 \\ (中国科学院南京地理与湖泊研究所,南京 210008)
}

\begin{abstract}
摘 要:20 世纪 80 年代之前,太湖有鱼类 107 种、 25 科, 属 4 个生态类型: 洄游型、江湖洄游型、河流型和湖沼型. 自 2002 年 9 月至 2006 年 1 月进行了太湖鱼类采集,共采得鱼类 60 种、18 科. 其中,除放流的鱼类外,都能在封闭的湖泊环境中完 成生命周期 (湖沼生态型) ; 团头鲂、鲮、银鲫和尼罗罗非鱼属移植种类. 团头鲂、鳙、鲢、草鱼和青鱼是从 20 世纪 60 年代 起每年向湖中放流的鱼类;鳗鳎则是自 1976 年起放流从长江采捕的鳗苗. 20 世纪 50 年末至 1985 年, 长江和太湖之间人 为隔断, 不能在静水中繁殖的鱼类在湖中消失, 自然鱼类资源下降; 加上过度捕捞和对繁殖群体缺少保护, 导致鱼类群体 小型化. 最后,对太湖渔业资源的优化进行了讨论,并进一步提出对策.
\end{abstract}

关键词:鱼类区系变化;渔获物分析;太湖

\section{Changes of the fish fauna and fish yield analysis in Lake Taihu}

\section{ZHU Songquan, LIU Zhengwen \& GU Xiaohong}

( Nanjing Institute of Geography and Limnology, Chinese Academy of Sciences, Nanjing 210008, P. R. China)

\begin{abstract}
Before 1980s, there were over 107 species belong to 25 families of fish in Lake Taihu, which can be divided into 4 ecological group, i. e. , migratory, river-lake migratory, potamophilus and limnocolous. A total of 60 species of fish belong to 18 families were collected in the lake from Sep. 2002 to Jan. 2006. Among them, 4 species (Megalobrama amblycephala, Cirrhinus molitorella, Carassius auratus gibelio and Oreochromis niloticus) were transplanted into the lake. From 1960s to now, grass carp, black carp, silver carp, bighead carp and blunt snout bream were stocked mainly with the artificial cultural fingerlings. From 1978 to now, the stocking object of eel (Anguilla japonica) were natural fry collected from the Yangtze River. During the end of 1950s to 1985, duo to “river-lake blocking” caused by artificial interruptions between the Yangtze River and Lake Taihu, the recruitment of those fish species that can not spawn in standing water were disappeared and natural fish resources of the lake had steadily declined. Moreover, reckless overfishing and inadequate protection of the spawners caused the diminution both in the size of fish species and of individual fishes, resulting the lake being dominated by species of small size as well as by populations of stunted growth. The optimization of fishery strategy for the lake has been put forward in view of the above results and environmental effect.
\end{abstract}

Keywords: Changes of fish fauna; fish yield analysis; Lake Taihu

太湖鱼类调查集中于 20 世纪 50 至 70 年代. 最早当推伍献文 ${ }^{[1]}$ 报道了在 1951 年采自五里湖的鱼类 63 种; 较晚的是王玉芬等 (1)记录鱼类 106 种 (有效名 98 种), 是当时记录种类最多者, 以后凡述及太湖鱼类 的都以 106 种为依据 ${ }^{[2]}$. 其间还有鱼类调查多篇: 如孙帼英等 (2)记录鱼类 57 种; 上海水产学院太湖资源调 查鱼类组 ${ }^{3}$ 记录鱼类 80 种, 水产部长江水产研究所等 ${ }^{4}$ 记录鱼类 89 种; 中国科学院南京地理研究所 ${ }^{[3]}$ 记录

* 2007-03-11 收稿;2007-07-06 收修改稿. 朱松泉,男,1935 年生, 研究员.

(1) 王玉芬, 蒋全文,谷庆义. 太湖的鱼类区系和组成, 1981 .

(2) 孙帼英, 王培潮. 太湖鱼类及其食性分析, 1959.

(3) 上海水产学院太湖资源调查渔业组. 太湖的鱼类,1964.

(4) 水产部长江水产研究所,江苏省水产科学研究所. 太湖鱼类区系, 1964. 
鱼类 63 种; 太湖、阳澄湖水产资源调查组 ${ }^{1}$ 记录太湖鱼类 101 种等.

2005 年倪勇、朱成德主编 ${ }^{[4]}$ 的《太湖鱼类志》出版,是其编写人员对上述报告中的鱼类进行整理,并尽 可能地到保存有太湖鱼类标本的单位进行核对,共记述鱼类 107 种、25 科、14 目. 反映了 20 世纪 $50-70$ 年 代太湖与长江畅通, 沟通江 - 湖间的以大运河为骨架的河网系统水质清新, 饵料资源丰富, 为江湖间鱼类通 行提供了优良的环境条件,是太湖天然鱼类发展的鼎盛时期.

朱松泉 ${ }^{[5]}$ 初步报道了太湖鱼类 48 种,但依旧在原来各采样点继续采集, 又增加了蓝藻水华多发的梅梁 湾设网篓采样. 这样, 从 2002 年 9 月到 2006 年 1 月,在太湖开捕期每个采样点都有 $2-3$ 次重复. 除了 2004 年报道的 48 种 $^{[5]}$ 外, 又新增鱼类 12 种,合计 60 种、18 科(附表 I). 这 12 种中,达氏鲌、拉氏狼牙鰕虎 鱼和尼罗罗非鱼采自梅梁湾. 鳊和鲮采自苏州东、西山湖区:鳊极稀少; 鲮则数量在增多,经常在䈤中能捕 起 6.7 尾. 6 种鱊亚科鱼类采自东、西山湖区和圩区池塘. 60 种鱼类中,团头鲂、鲮、银鲫和尼罗罗非鱼属非 自然分布鱼类,除团头鲂自 1970 年起每年由人工放流外,其余都是被动移植鱼类. 如银鲫只在东、西山湖 区发现 1 尾,可能是洪水年从养殖区逃逸的; 尼罗罗非鱼采得多尾,体长 $50-70 \mathrm{~cm}$, 据传是附近灵山香客的 放生鱼; 鲮可能也是逃逸鱼. 但后两者能否成为太湖自然种群, 值得关注. 草鱼、鳙、鲢、青鱼和鳗鲡都是放 流鱼类, 从上世纪 50 年代起试行四大家鱼人工放流以来, 几乎每年都放流, 只是青鱼和鳗鲡要视青鱼种和 鳗苗供应情况而定.

\section{1 鱼类区系变化}

这次采集到的 60 种与《太湖鱼类志》的 107 种比较,除放流鱼团头鲂是共有的,鲮、银鲫和尼罗罗非鱼 是新增的移植鱼外, 实际减少了 55 种, 它们是: 中华鲟、鳗鲡、鲥、胭脂鱼、宽鯺鱲、马口鱼、尖头鱤、青鱼、草 鱼、鲩、鯮、鱤、贝氏鲦、鲂、尖头鲌、寡鳞飘鱼、飘鱼、银鲖、黄尾鲖、细鳞鲖、圆吻鲖、唇鳃、银鮈、点纹银鮈、铜 鱼、吻鮈、福建小鳔鮈、小口小鳔鮈、蛇鮈、长蛇鮈、光唇蛇鮈、鲢、鳙、无须鱊、大口鱊、花斑副沙鳅、中华花鲀、

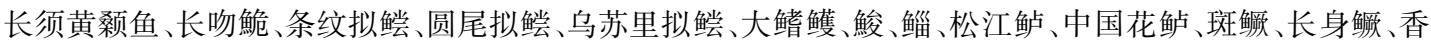
鲫、波氏吻鰕虎鱼、须鳗鰕虎鱼、月鳢、窄体舌鳎、暗纹东方鲀等.

自 1958 年起,沿江通江河口先后建闸, 以后不断开挖泄洪河道,修水闸、船闸,修环湖大堤和复堤等水 利工程,20 世纪 70 年代达到高潮,至 1985 年告一段落. 与此同时,沟通太湖和长江的、以大运河为骨架的 河网水系污染加剧. 这样, 江湖间的两重阻隔是太湖鱼类种类减少和多样性降低的主要原因. 长江通江湖 泊的鱼类可分为洄游型、江河洄游型、河流型和湖沼型四种生态型 ${ }^{[6]}$. 除洄游型的刀鲚、银鱼类、间下鱵、鳗 鰕虎鱼科鱼类在江湖阻隔后尚能在湖中生活外, 现存太湖的鱼类都属湖沼型, 它们都能在湖中完成生命 周期.

\section{2 渔获物分析}

目前, 太湖渔获物分为刀鲚、银鱼类、大中型鱼类和小杂鱼四类,其中小杂鱼不包括刀魰和银鱼,但包括 大中型鱼类的幼鱼. 为保护鱼类资源, 太湖渔业管理委员会 (太湖渔管会) 规定自 1998 年起,每年 2 月 1 日 至 8 月 31 日为禁渔期,9 月 1 日至翌年元月为开捕期.

\section{1 刀鲚产量增长明显银鱼 (主要是大银鱼和陈氏短吻银鱼) 产量波动较大}

20 世纪 50 年代刀鲚平均年产量 $2296.8 \mathrm{t}^{[4]}$ [占总产量 (包括虾、蟹产量,下同) $33.3 \%$ ],60 年代为 $5430.2 \mathrm{t}$ (占 $55.8 \%$ ),70 年代为 $6383.1 \mathrm{t}$ (占 $56.5 \%$ ), 80 年代为 $5952.5 \mathrm{t}$ (占 $41.9 \%$ ), 90 年代为 $9249.5 \mathrm{t}$ (占 $51.8 \%), 2000-2003$ 年为 $16910.8 \mathrm{t}$ (占 $61.1 \%$ ).

20 世纪 50 年代银鱼平均年产量 $754.2 \mathrm{t}^{[4]}$ (占总产量的 $10.9 \%$ ),60 年代为 $551.2 \mathrm{t}($ 占 $5.7 \%$ ),70 年代 为 $731.0 \mathrm{t}$ (占 $6.3 \%$ ), 80 年代为 $1381.3 \mathrm{t}$ (占 $9.7 \%$ ). 80 年代中后期起, 银鱼销售价格大幅上涨, 银鱼在封 湖休渔期间作为重点保护对象, 1984-1992 年 9 年的平均产量达到 1707.2 t. 产量只占总产量的 $11.4 \%$, 但 产值占总产值的 50\%-60\%. 由于价格高, 银鱼的捕捞压力不断加大, 产量一度跌人低谷. 20 世纪 $70-80$

(1) 太湖、阳澄湖水产资源调查组. 太湖水产资源和渔业调查报告, 1975. 
年代, 大银鱼和陈氏短吻银鱼每年的产量大体接近; 陈氏短吻银鱼有秋季和春季两个产卵群, 同样, 秋群和 春群也各占资源量的一半. 20 世纪 90 年代后, 大银鱼资源量急剧减少, 由 1989 年占银鱼产量的 $65.34 \%$, 至 1994 年仅为 $9.46 \% .1997$ 年春汛银鱼停捕后, 银鱼产量有所回升.

\section{2 大中型鱼类中天然鱼类弱化、小杂鱼数量增多}

太湖渔管会的渔获物统计中,大中型鱼类只统计放流鱼类和鲌类, 天然鱼类无统计; 小杂鱼只有重量而 无分类统计. 因放流鱼类的产量决定当年放流鱼种的数量和规格, 不能反映种群自身的消长规律. 为弥补 其不足, 我们在有水草的东、西山湖区 (苏州湖区) 和无水草的大浦湖区 (宜兴湖区) 各选定一只网䈤, 进行 一个捕捞季的渔获物测定,小杂鱼用抽样法 (表 1 和表 2).

表 1 苏州、宜兴湖区网籍渔获物测定

Tab. 1 Composition of fish yield in catches of fish-trap in Lake Taihu near Suzhou \& Yixing

\begin{tabular}{|c|c|c|c|c|c|c|}
\hline \multirow{2}{*}{ 鱼类 } & \multicolumn{6}{|c|}{ 苏州湖区 $(2003-09-10$ 至 $2004-01-15)$ 宜兴湖区 $(2003-09-13$ 至 $2004-01-08)$} \\
\hline & 总重 $(g)$ & 平均体重 $(\mathrm{g})$ & 占总产量 $(\%)$ & 总重 $(g)$ & 平均体重 $(\mathrm{g})$ & 产量 (\%) \\
\hline 放流种类 & 1779200 & - & 42.20 & 151600 & - & 1.85 \\
\hline 草鱼 & 1640000 & 1564.89 & 38.89 & 1000 & 1000. 00 & 0. 01 \\
\hline 团头鲂 & 84550 & 578.77 & 2.01 & - & - & - \\
\hline 鲢、鳙 & 45050 & 919.39 & 1.07 & 146850 & 917.81 & 1.79 \\
\hline 鳗鲡 & 7400 & 528.57 & 0. 18 & 500 & 250. 00 & 0.01 \\
\hline 青鱼 & 2200 & 1100. 00 & 0.05 & 3250 & 3250. 00 & 0.04 \\
\hline 自然种群 & 956215 & - & 22.69 & 4855307 & & 59.28 \\
\hline 鲤 & 810300 & 615.26 & 19.22 & 4077818 & 515.05 & 49.77 \\
\hline 鲌类 & 85100 & 303.90 & 2.02 & 86869 & 79.49 & 1.06 \\
\hline 鳜 & 50095 & 266.67 & 1.19 & - & - & - \\
\hline 拟刺鳊鮈 & 6325 & 85.00 & 0.15 & - & - & - \\
\hline 赤眼鳟 & 3795 & 85.00 & 0. 09 & - & - & - \\
\hline 鲇 & 600 & 600. 00 & 0.02 & 1220 & 406.00 & 0.02 \\
\hline 鲫 & - & - & - & 580500 & 244.93 & 7.09 \\
\hline 黄颡鱼 & - & - & - & 108900 & 181.50 & 1.34 \\
\hline 小杂鱼 & 1481297 & - & 35.11 & 3184823 & - & 38.87 \\
\hline 总 计 & 4216712 & - & 100. 00 & 8191730 & - & 100. 00 \\
\hline
\end{tabular}

由表 1 可知,因环境不同 (如水草有无),鱼类组成也不同. 其中苏州、宜兴两湖区共有的种是: 草鱼、 鲢、鳙、青鱼、鳗鲡、红鯺原鲌、尧唃红鲌、蒙古红鲌、鲇、鲤、鲫、黄颞鱼、大鯺鱊、鲦和似鳊等, 苏州湖区另有的 种是:团头鲂、鳜、大眼䱻、拟刺鳊鮈、赤眼䲡、似鱎、麦穗鱼、黑鲔鳈和棒花鱼等 9 种; 宜兴湖区另有的种是: 光泽黄颞鱼、瓦氏黄颡鱼、花䱻和刀鲚等 4 种, 其中瓦氏黄颡鱼是太湖的新记录. 苏州湖区的放流鱼类和天 然鱼类的量接近, 分别占总产量的 $42.20 \%$ 和 $57.80 \%$, 而宜兴湖区分别为 $1.85 \%$ 和 $98.15 \%$; 前者草食性鱼 类较多, 后者则以鲤、鲫为主. 团头鲂是 1970 年移植进太湖的, 以后几乎年年由人工放流. 团头鲂是静水生 活的鱼类, 能在湖中繁殖生长, 繁殖时对水流的要求并不高, 但至今未有迹象表明其在太湖已成为自然种 群. 据在苏州湖区网䈤渔获物测定,5个月的开捕期内共起捕团头鲂 146 尾,其中 9-11 月捕到 145 尾, 12 月捕到 1 尾, 翌年元月 0 尾. 可见,团头鲂体型特殊, 起水率高, 加之放流的鱼种数量不多, 几乎没有留下足 够的繁殖群体至春季参与繁殖,这可能是其未能成为太湖自然种群的原因之一.

太湖现有鲌类 4 种, 但只有尧嘴红鲌最名贵, 捕捞强度大, 数量最少; 数量最多的是红鯺原鲌, 个体小, 在苏州湖区占小杂鱼的 26\% (表 2). 20 世纪 50 年代因受人为干扰少, $1952-1958$ 年的年平均产量为 $406.4 \mathrm{t}$, 占捕捞总产量的 $5.9 \% ; 2003$ 年为 $153.85 \mathrm{t}$, 只占总渔产量的 $0.55 \%$. 
小杂鱼 (表 2) 占捕捞量的 $30 \%$ 以上,一部分是小型鱼类,而相当数量是起捕的幼鱼. 篓的取鱼部网目 5 $\mathrm{cm}$, 因用的网线很粗, 相对空间很小, 所以渔获物中体长 $10 \mathrm{~mm}$ 、体重 $10 \mathrm{~g}$ 以下的鱼占有很大比重, 表明捕 捞强度很大.

表 2 苏州、宜兴湖区网䈤渔获小杂鱼组成

Tab. 2 Fishes of small size and stunted growth in catches of fish-trip in Lake Taihu near Suzhou \& Yixing

\begin{tabular}{|c|c|c|c|c|c|c|}
\hline \multirow{2}{*}{ 鱼类 } & \multicolumn{6}{|c|}{ 苏州湖区 $(2003-09-10$ 至 $2004-01-15)$ 宜兴湖区 $(2003-09-13$ 至 $2004-01-08)$} \\
\hline & 总重 $(\mathrm{g})$ & 平均体重 $(\mathrm{g})$ & 占总产量 $(\%)$ & 总重 $(g)$ & 平均体重 $(\mathrm{g}$ & 产量 $(\%)$ \\
\hline 大鯺鱊 & 605116 & 6.3 & 40.85 & 122565 & 7.8 & 3.85 \\
\hline 红鯺原鲌 & 386781 & 17.2 & 26. 11 & - & - & - \\
\hline 鲤 & 141682 & 26.8 & 9.57 & 337035 & 99.0 & 10.58 \\
\hline 鲦 & 117773 & 22.0 & 7.95 & 35683 & 18.0 & 1.12 \\
\hline 鲫 & 97821 & 18.2 & 6.60 & 2652096 & 46.0 & 83.27 \\
\hline 尧嘴鲌 & 56278 & 22.2 & 3.80 & - & - & - \\
\hline 似鱎 & 36489 & 7.9 & 2.46 & - & - & - \\
\hline 麦穗鱼 & 17352 & 10.7 & 1.17 & - & - & - \\
\hline 黑鳍鳈 & 7978 & 6.4 & 0.54 & - & - & - \\
\hline 黄颡鱼 & 5449 & 9.5 & 0.37 & - & - & - \\
\hline 棒花鱼 & 5333 & 10.0 & 0.36 & - & - & - \\
\hline 赤眼䲡 & 1980 & 60.0 & 0.13 & - & - & - \\
\hline 似鳊 & 1265 & 25.0 & 0.09 & 20427 & 30.0 & 0.64 \\
\hline 刀魰 & - & - & - & 17017 & 25.0 & 0.54 \\
\hline 总计 & 1481297 & - & 100.00 & 3184823 & - & 100.00 \\
\hline
\end{tabular}

捕捞分类产量反映了近年太湖渔获物的结构. 太湖渔管会提供的统计数据表明,2003 年捕捞分类产量 依次为: 刀鲚 $19747.50 \mathrm{t}$ 、小杂鱼 $3036.55 \mathrm{t}$ 、鲫 $1461.95 \mathrm{t}$ 、鲤 $1042.00 \mathrm{t}$ 、银鱼类 $745.92 \mathrm{t}$ 、鳙 $726.00 \mathrm{t}$ 、鲢 493.55 $\mathrm{t}$ 、草鱼 $267.60 \mathrm{t}$ 、团头鲂 $244.00 \mathrm{t}$ 、鲌类 $153.85 \mathrm{t}$ 、青鱼 $60.95 \mathrm{t}$ 、鳗鲡 $6.55 \mathrm{t}$; 总渔产量 (全部鱼的产量) 27986.42 t. 其中刀魰占总渔产量的 $70.56 \%$, 小杂鱼占 $10.85 \%$.

综上所述, 太湖鱼类区系的明显变化和不断加大的捕捞强度, 以及小型鱼类较之大中型鱼类具有较强 的补偿调节能力, 环境变化和捕捞对其种群产生的伤害较小. 导致刀鲚产量不断增长, 幼鱼比例增大, 大中 型鱼类以及市场价格高的鱼类产量波动明显或萎缩.

\section{3 讨论}

水利建设造成江湖阻隔,切断了太湖和长江鱼类的交换. 刘建康院士指出: “隔断这种交换是注定要给 湖里 (最后也给长江里) 的自然鱼类资源带来衰退……因此, 人工放养应运而生” ${ }^{[7]}$. 太湖渔管会很早就认 识到这个问题, 用每年向太湖放流鱼种的方法以补充鱼类资源的不足.下面仅就有关的渔业问题进行讨论， 提出建议,供有关部门参考.

\section{1 建议开捕期从现在的 9 月 1 日延至 10 月 1 日,使禁渔期延长 1 个月}

原因有三:一是就太湖地区而言,鱼类最适生长期是 6-10月,9月的平均气温仅比 8 月下降约 $4^{\circ} \mathrm{C}$, 仍 是鱼类生长的最好时期. 二是 9 月气温太高, 渔民们为了提高鱼货上市的鲜度, 要在凌晨 $3 、 4$ 点出湖收网, 增加了劳动强度. 三是以苏州湖区网䈤为例, 9 月起捕的渔产量占开捕期产量的 40\%,10 月为 37\%,11 和 12 两个月为 $21 \%$, 翌年元月仅 $2 \%$. 将禁渔期延长一个月, 无论对放流鱼的生长, 自然鱼类的增值, 以及提 高鱼货质量和降低渔民劳动强度等考虑, 都是有利的.

\section{2 扩大放流鱼的种类,提高放流鱼的规格}

事实证明, 人工放流鱼类是太湖增加鱼类资源量, 调整鱼类结构的最直接和有效的方法. 在渔获物组 
成中, 宜兴湖区放流种类产量仅占渔获物的 $1.85 \%$; 因草食性鱼类都分布在有水草的湖区, 故苏州湖区放 流种类产量占 $42.20 \%$ (表 1). 以宜兴湖区为代表的西太湖区, 虽缺少水草, 但分布有丰富的底栖动物如黄 蚬等, 以及敞水性的小型鱼类如刀鲚等, 也是食水生昆虫、底栖动物的鱼类如花䱻分布较多的湖区. 可见, 放流种类除常规种类外, 还应注意天然饵料丰富程度来配置放流鱼类. 建议大量放流经济价值高、以底栖 动物为食的青鱼、花䱻, 适当放流尧嘴鲌. 由于太湖优质水草资源衰减明显, 宜控制草鱼的放流量, 增加团 头鲂的放流量. 如前述, 增加团头鲂放流量, 使其在湖中有相当多的剩余群体, 达到自然繁殖的目的. 凡放 流应尽可能培养大规格鱼种, 可明显提高成活率和生长速率.

\section{3 在梅梁湾大规模围养鲢、鳙, 提高湖泊渔产量与治理湖水富营养化相结合}

武昌东湖是一个城郊湖泊, 地理环境与梅梁湾接近. 当地通过调查研究提出了在湖中放养鲢、鳙的五 项措施: 放养鱼种要合理, 要生产大量的大规格鱼种, 栏鱼设备要改进, 凶猛鱼类要控制, 以及捕鱼效率要提 高. 围养鲢、鳙作为治理湖水富营养化的依据是, 放到湖里的鲢、鳙是不投饲料的, 是以现成的天然饵料为 食. 即每年进人水中的有机物, 通过食物链转化为鱼肉, 再通过捕捞移出水面. 东湖养鲢、鳙已取得成功经 验, 产量有很大提高, 至今已无人会担心大规模放养得不偿失的问题.

当然, 治理富营养化要采取综合措施, 放养鲢、鳙不是治理富营养化的唯一方法, 但刘建康院士指出: “如果东湖没有进行鱼类放养的话, 这个湖泊的富营养化的加速很可能比现在严重的多” ${ }^{[7]}$. 梅梁湾频发蓝 藻水华, 每次大暴发都会带来很大经济损失, 积极推进生态治污是重要措施之一. 太湖大中型鱼类资源量 并不高, 借鉴武汉东湖经验大规模放养鲢、鳙, 利用太湖渔政管理方面的优势, 可以在经济、环境和社会三大 效益方面取得全面丰收.

\section{4 关注小杂鱼的利用}

一是保护幼鱼. 小杂鱼中有大量幼鱼, 如鲤、鲫 (表 2), 无疑是捕捞强度过大的牺牲品. 有时, 一边是渔 管会放流鲤的夏花以增加鱼类资源, 一边渔民捕出的却是鲤鱼种. 如果捕捞强度得不到有效控制, 这种得 不偿失的事会经常发生. 严格控制网目, 捕大留小, 应是不难做到的. 二是重视小型鱼类的加工, 提高其附 加值. 太湖小型鱼类不少, 如刀鲚、鲦、鱊类、红鯺原鲌等, 仅刀鲚产量接近 20000t. 这些鱼体型规正, 肉质不 错, 是加工的好原料; 而目前这些鱼的收购价仅 1 元 $/ \mathrm{kg}$, 存在增值空间; 更重要的还可以转移部分捕捞劳 力. 必须摒弃 “一把刀, 两把盐” 的落后生产方式. 应该是 “建好两条冷冻链, 保证原料鱼和产品的鲜度; 完 善标准化体系,重视品牌效应; 引导消费; 建立高效率的流通、营销网络” ${ }^{[8]}$.

致谢: 感谢朱成德、陈校辉、叶佳林、刘平平、密根兴、陈粉兰和陈文宽等同志在提供鱼类分布线索或采集标 本过程中给予的帮助.

\section{4 参考文献}

１］伍献文. 五里湖 1951 年湖泊调查 (五) : 鱼类区系及其分析. 水生生物学集刊,1962,(1):99-113.

[2] 张玉书. 渔业与生物资源. 见:孙顺才等主编. 太湖. 北京: 海洋出版社, 1993:159-195.

[3] 中国科学院南京地理研究所. 太湖综合调查初步报告. 北京:科学出版社, 1965:62-64.

[4] 倪 勇,朱成德主编. 太湖鱼类志. 上海: 上海科学技术出版社,2005:61-227.

[5] 朱松泉. 2002-2003 年太湖鱼类学调查. 湖泊科学, 2004,16(2):120-124.

[6] 梁秩醈, 周春生, 黄鹤年. 长江中游通江湖泊一一五湖的鱼类组成及其季节变化. 海洋与湖沼, 1981, $12(5): 468-478$.

[7] 刘建康. 长江中下游流域的湖泊及其渔业利用问题. 见: 刘建康主编. 东湖生态学研究 (二). 北京: 科学出版社, $1995: 1-25$.

[8] 朱松泉. 大宗淡水渔产品产业化的分析与展望. 水利渔业,2003,23(2):1-3. 
附表 I 太湖鱼类名录 (Appendix I Fish fauna of Lake Taihu)

I 鳗鲡目 Anguilliformes i 鳗鲡科 Anguillidae 1 鳗鲡 Anguilla japonica Temminck et Schlegel *

II 鯡形目 Clupeiformes ii 鳀科 Engraulidae

2 刀鲚 Coilia nasus Temminck et Schlegel

III 鲤形目 Cypriniformes iii 鲤科 Cyprinidae

3 中华细鲫 Aphyocypris chinensis Günther

4 青鱼 Mylopharyngodon piceus (Richardson) *

5 草鱼 Ctenopharyngodon idellus (Cuvier et Valenciennes ) *

6 赤眼䲡 Squaliobarbus curriculus (Richardson)

7 鲦 Hemiculter leucisculus (Basilewsky)

8 红鰙原鲌 Cultrichthys erythropterus (Basilewsky)

9 鳊 Parabramis pekinensis (Basilewsky)

10 团头鲂 Megalobrama amblycephala Yih ${ }^{*}, * *$

11 尧嘴鲌 Culter alburnus Basilewsky

12 达氏鲌 C. dabryi Bleeker

13 蒙古鲌 C. mongolicus (Basilewsky)

14 似鱎 Toxobramis swinhonis Günther

15 似鳊 Pseudobrama simony (Bleeker)

16 鳙 Aristichthys nobilis (Richardson) *

17 鲢 Hypophthalmichthys molitrix (Cuvier et Valenciennes) *

18 花鳁 Hemibarbus maculatus Bleeker

19 似刺鳊鮈 Paracanthobrama guichenoti Bleeker

20 麦穗鱼Pseudorasbora parva (Temminck et Schlegel)

21 黑鳍鳈 Sarcocheilichthys nigripinnis (Günther)

22 华鳈 $S$. sinensis Bleeker

23 亮银鮈 Squalidus nitens (Günther)

24 棒花鱼 Abbottina rivularis (Basilewsky)

25 短须鱊Acheilognathus barbatulus Günther

26 兴凯鱊 A. chankaensis (Dybowsky)

27 大鳀鱊 A. macropterus (Bleeker)

28 越南鱊 A. tonkinensis (Vaillant)

29 革条鱊 $A$. himantegus Günther

30 彩鱊 A. imberbis Günther

31 方氏鰟鮍 Rhodeus fangi (Miao)

32 高体鰟鮍 $R$. ocellatus (Kner)

33 中华鰟鮍 $R$. sinensis Günther

34 鲮 Cirrhinus molitorella (Cuvier et Valenciennes) ***

35 鲤 Cyprinus carpio Linnaeus

36 鲫 Carassius auratus auratus (Linnaeus)

37 银鲫 Carassius auratus gibelio (Bloch) ${ }^{* *}$ iv 鳅科 Cobitidae

38 泥鳅 Misgurnus anguillicaudatus (Cantor)

39 大鳞泥鱾 Paramisgurnus dabryanus Sauvage

IV 鲇形目 Siluriformes $\mathrm{v}$ 鲿科 Bagridae

40 黄颡鱼 Pelteobagrus fulvidraco (Richardson)

41 光泽黄颡鱼 $P$. nitidus (Sauvage et Dabry)

42 瓦氏黄颞鱼 P.vachelli (Richardson)

vi 鲇科 Siluridae

43 鲇 Silurus asotus Linnaeus

V 胡瓜鱼目 Osmeriformes vii 银鱼科 Salangidae

44 大银鱼 Protosalanx hyalocranius (Abbott)

45 乔氏短吻银鱼 Salangichthys jordani（Wakiya et Takahasi)

46 陈氏短吻银鱼 S. tangkahkeii（Wu)

47 短吻间银鱼 Hemisalanx brachyrostris (Fang)

VI 领针鱼目 Beloniformes viii 鱵科 Hemirhamphidae 48 间下鱵 Hyporhamphus intermedius (Cantor)

VII 鳉形目 Cyprinodontiformes ix 鳉科 Oryziatidae

49 青鳞 Oryzias latipes sinensis Chen, Uwa et $\mathrm{Chu}^{1}{ }^{1}$

\section{VIII 合鳃目 Synbranchiformes}

$\mathrm{x}$ 合鳃科 Synbranchidae

50 黄鳝 Monopterus albus (Zuiew)

\section{IX 鲇形目 Perciformes}

xi 鮨科 Serranidae

51 鳜 Siniperca chuatsi (Basilewsky)

52 大眼鲭 S. kneri Garman

xii 丽鱼科 Cichlidae

53 尼罗罗非鱼 Oreochromis niloticus (Linnaeus) ** xiii 塘鳢科 Eleotridae

54 小黄䁫鱼 Micropercops swinhonis (Günther)

55 河川沙塘鳢 Odontobutis potamophila (Günther) xiv 鰕虎鱼科 Gobiidae

56 子陵吻鰕虎鱼 Rhinogobius giurinus (Rütter) $\mathrm{xv}$ 鳗鰕虎鱼科 Taenioididae

57 拉氏狼牙鰕虎鱼 Odontamblyopus lacepedii ( Tem. et Schl. . )

xvi 斗鱼科 Belontiidae

58 圆尾斗鱼 Macropodus chinensis (Bloch) xvii 鳢科 Channidae

59 乌鳢 Channa argus (Cantor)

xviii 刺鲀科 Mastacembelidae

60 中华刺鳅 Mastacembelus sinensis (Bleeker)

* 人工放流种类; $* *$ 移植或被动移植种类;

1)《太湖鱼类志》为: 青鲟 Oryzias latipes (Temminck et Schlegel);

2 )《太湖鱼类志》为:红狼牙鰕虎鱼 Odontamblyopus rubicundus (Hamiltom). 